\title{
BMJ Open Effects of family group conferences among high-risk patients of chronic disability and their significant others: study protocol for a multicentre controlled trial
}

Chantal F Hillebregt, ${ }^{1}$ Eline W M Scholten, ${ }^{1}$ Marjolijn Ketelaar, ${ }^{1}$ Marcel W M Post, ${ }^{1,2}$ Johanna M A Visser-Meily ${ }^{1}$

To cite: Hillebregt CF, Scholten EWM, Ketelaar M, et al. Effects of family group conferences among high-risk patients of chronic disability and their significant others: study protocol for a multicentre controlled trial. BMJ Open 2018;8:e018883. doi:10.1136/ bmjopen-2017-018883

\section{- Prepublication history for} this paper is available online. To view these files, please visit the journal online (http://dx.doi. org/10.1136/bmjopen-2017018883).

Received 28 July 2017 Revised 21 December 2017 Accepted 15 January 2018

Check for updates

${ }^{1}$ Center of Excellence in Rehabilitation Medicine, Brain Center Rudolf Magnus, University Medical Center Utrecht, University Utrecht and De Hoogstraat Rehabilitation, the Netherlands

${ }^{2}$ Department of Rehabilitation Medicine, University of Groningen, University Medical Center Groningen, Groningen, The Netherlands

\section{Correspondence to} Dr Johanna M A Visser-Meily; j.m.a.visser-meily@umcutrecht. $\mathrm{nl}$

\section{ABSTRACT}

Introduction Many patients and family members experience a large gap between the protected environment during inpatient medical rehabilitation and life in the community after discharge. They feel insufficiently prepared to cope with the consequences of their disability in daily life. This study protocol describes the design measuring the effectiveness and implementation of family group conferences on the empowerment of patients with a high risk of chronic disability and their significant others.

Methods and analysis A multicentre controlled trial will be carried out in 12 rehabilitation centres in the Netherlands. A total of 328 clinically admitted patients will participate ( $\geq 18$ years, diagnosed with acquired brain injury, spinal cord injury or leg amputation), and their significant others will be included. During three family group conferences, supported by the social worker, the patient, significant other and their social network will be stimulated in collaboration, to set up participation goals, determine the needed help and make a concrete action plan. Self-reported questionnaires will be collected at baseline, clinical discharge, and 3 months and 6 months following clinical discharge. Empowerment as the primary outcome is operationalised as self-efficacy and participation. Secondary outcome measures are psychological (eg, coping, neuroticism) and environmental (eg, family functioning, social support) factors. This is the first controlled trial evaluating the effectiveness of family group conferences in rehabilitation medicine among adult patients and their significant others, providing us with knowledge in improving rehabilitation care.

Ethics and dissemination This study has been approved by the Medical Ethics Committee of the University Medical Center Utrecht (number 15-617/C). The results will be published in peer-reviewed journals and presented in local, national and international conferences.

Trial registration number NTR5742; Pre-results.

\section{BACKGROUND}

The majority of patients admitted to inpatient rehabilitation after onset of a serious physical condition return to their homes after discharge. There they are faced with a
Strengths and limitations of this study

- This study is the first multicentre controlled trial evaluating the effectiveness and the implementation of 'Family Group Conferences' in rehabilitation medicine, with the potential to improve future treatment.

- Rehabilitation treatment focusing on both patient, significant other and social network simultaneously is relatively new and expected to be more effective than focusing solely on the patient.

- Study limitations come with pragmatic reasons that prevent random treatment assignment.

new reality of coping with chronic physical and/or cognitive disabilities and possible dependence on others. Many patients feel restricted in their social participation ${ }^{12}$ and experience adverse psychological outcomes (eg, depression, anxiety, feelings of helplessness and poor quality of life). ${ }^{34}$ Their family members may also experience difficulties in aspects of caring, ${ }^{56}$ high levels of burden and impaired quality of life. ${ }^{7-10} \mathrm{~A}$ large gap is experienced by many patients and their relatives between the protected environment during inpatient rehabilitation and life in the community, feeling insufficiently prepared to cope with the disability in daily life. ${ }^{1112}$ Existing interventions focus primarily on the needs of patients, not on the needs of the significant others ${ }^{13}$ (usually the partner, but can be everyone who is important in one's wellbeing). Empowering both patients and significant others as part of rehabilitation treatment may help to reduce this gap, reduce distress and enhance participation in daily activities. 


\section{Family-centred rehabilitation}

Medical rehabilitation in the Netherlands often exists as a period of clinical admittance followed by a period of outpatient care after discharge. A comprehensive assessment and treatment of functioning is performed by multidisciplinary teams (ie, physical, psychological, social and communicative functioning, and functioning regarding activities of daily living). ${ }^{14}$

The awareness of the important role of the family during rehabilitation treatment is growing, ${ }^{13} 15$ and although family meetings are regularly conducted in a number of inpatient settings ${ }^{16}$ there is limited empirical research in this area. ${ }^{17} 18$ Furthermore, these family meetings are usually professional-driven, not family-driven, and consequently power disparities between patient, family and professional are still present, restricting full participation of both the patient and the family in the rehabilitation. 161920

A method focusing on empowerment and active involvement of patients and significant others is family-centred care, which has the following key values ${ }^{15} 2122$ :

1. recognising patients and their families as the experts of their own needs

2. promoting partnership between patients, family and health professionals

3. supporting the patients and the family's role in decision making.

Whereas these family-centred values are widely implemented in youth healthcare, this proved more difficult in the healthcare for adult patients in general, ${ }^{15} 23$ although there are some examples of family meetings in dementia care with a more family-centred approach. ${ }^{24}{ }^{25}$ In rehabilitation care though, these examples are sparse. ${ }^{26-28}$

\section{Family group conference}

One approach incorporating these family-centred values is the 'Family Group Conference' (FGC) model. FGC originates in New Zealand, where FGC was legislated in 1989 as the decision-making process to be used in cases of child abuse, neglect and youth offending. ${ }^{29}{ }^{30}$ FGC offered a new perspective that challenges paternalistic practices, in which instead of professionals assessing problems, the family and the person in need have the main voice in what concerns them. ${ }^{31}$ A FGC is a structured meeting in which the person in need and members of their social network reflect on goals with respect to participation in daily activities. During FGCs the participants share ideas on possible solutions to achieve these goals and decide on a concrete plan to support the person in need in the way they want. Drawing up an action plan with involvement of a wider network is one of the three important philosophical pillars of the original FGC model in child care. Second is using an independent coordinator who prepares the FGC with collaborating family members, and the third is using private time for the family group to develop a plan. ${ }^{31-33}$ The FGC approach is 'family driven', meaning that the approach is not aimed at the family, but achieves results through the contributions of the family. ${ }^{31}$
A major difference with current family meetings is that the person in need together with their social network sets the agenda and develops the plan, not the professional. The traditional method where professionals are in control is abandoned, ${ }^{34}$ making the FGC rather proactive than reactive, and more responsive to the family's needs. ${ }^{13}$ As the FGC stimulates the decision-making process, a rearrangement of tasks and responsibilities takes place, enlarging the empowerment of the person in need ${ }^{35}$ by shifting the balance of power towards the family within the decision-making process. ${ }^{34}$

The major advantages are that FGC uses resources already existing within society, namely the family and others, ${ }^{36}$ who are often better able to find workable solutions $^{34}$ consistent with their own culture, lifestyle and history than professionals. ${ }^{37}$

Research examining the impact of FGC is mainly based on qualitative evaluation research. ${ }^{38}$ Evidence supporting the effectiveness of the FGC approach is still sparse ${ }^{38-40}$ due to study designs lacking a control group, ${ }^{3841}$ although positive results were seen in studies with people with intellectual disabilities ${ }^{42}$ and in child welfare. ${ }^{43}$ So far, there has been no research conducted evaluating the effectiveness of FGC among the adult population and their social network in the field of rehabilitation medicine. In response to this lack of knowledge, an FGC model is developed and implemented, adapted to the medical rehabilitation setting, evaluating the effectiveness in a multicentre controlled trial embedded in a larger prospective cohort study. A conceptual empowerment framework of the study is introduced, outlining the positioning of FGC in rehabilitation medicine.

\section{Study aims}

The following are the specific aims of the study:

- examine the hypothesis if optimising the decision-making process during FGCs gives an increase of empowerment in both the patient and the significant other

- examine the effectiveness of FGC compared with regular rehabilitation care to increase empowerment of patients and families

- identify predictors at admission to inpatient rehabilitation of long-term empowerment in patients with physical disabilities and their significant others

- clarify causal mechanisms and identify contextual factors associated with variation in outcomes to optimise the design of future interventions by conducting a process evaluation assessing fidelity and quality of implementation.

\section{Conceptual framework}

The study is conceptualised using the framework outlined in figure 1 .

\section{Empowerment}

The concept of empowerment is operationalised in diverging ways. ${ }^{35} 44$ The $\mathrm{WHO}^{46}$ has adopted the 


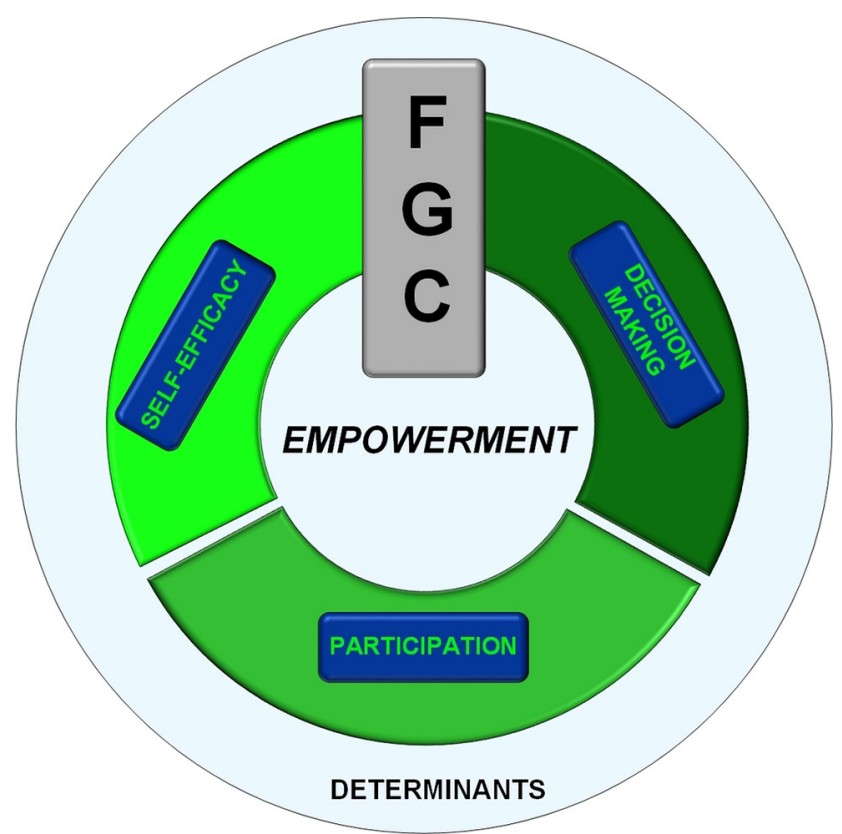

Figure 1 Family group conference (FGC) empowerment model (edited by Hillebregt \& Scholten 2017) Reproduced with permission from Zimmerman MA. ${ }^{109}$

definition of Rappaport ${ }^{47}$ : 'empowerment is a process by which people, organizations and communities gain mastery over their affairs' (p122). In the last decade many publications have been written discussing empowerment in the context of rehabilitation, but relatively little attention has been paid to exploring the relationships between the various empowerment variables and rehabilitation outcomes. $^{44} 48$

The intrapersonal, interactional and behavioural framework of psychological empowerment is used to identify the outcome of FGC. ${ }^{48}$ The intrapersonal component refers to how people think about themselves, the interactional component refers to how they also relate to their social environment, and the behavioural component refers to the specific actions the individual takes to participate in the community. ${ }^{48}$ An increasing number of scientists stress the importance of a fourth component: social and interpersonal relations, also called relational empowerment. $^{49-53}$ In the context of FGC it explains the importance of the support from members in the social network and the necessity of having meaningful relationships. ${ }^{54}$

Overall, on the level of the individual, empowerment in FGC in medical rehabilitation can be understood as the process to enhance control over life situations, participation and social relations ${ }^{4655}$ through influencing and increasing the decision-making process in families, with self-efficacy and participation as important outcomes. 4656

\section{Self-efficacy and participation}

The hypothesis is that due to optimising the decision-making process during FGCs by including the family, self-efficacy and participation of both the patient and the significant other increase.
Self-efficacy is a core concept of the social cognitive theory and refers to perceptions about one's ability to achieve desired outcomes. ${ }^{57-59}$ Self-efficacy can, therefore, be seen as the psychological component of empowerment. Participation is a core concept of the International Classification of Functioning, Disability and Health and refers to the involvement in a life situation and thereby as the behavioural component of empowerment. ${ }^{60}$ Self-efficacy and participation are closely interrelated. Research shows that patients with higher self-efficacy are able to function better, show increased participation and satisfaction with their participation, and experience higher quality of life than patients with lower self-efficacy. ${ }^{61-63}$ In informal caregivers, higher self-efficacy is related to less feelings of burden and distress. ${ }^{64} 65$

\section{Decision making}

The adaptive practice model of Feldman $e t a t^{66}$ is used to discuss and clarify a decision-making interaction approach during the FGCs, where the goals are to have (1) productive decision making, (2) family group inclusion and (3) professional supportiveness. ${ }^{67}$ The aim of the interaction between patient/significant other, the family and the professional is to optimise the family decision making, being a process of alternate phases of sharing knowledge and skills, coaching, shared decision making, and eventually fully empowered participation.

In the adaptive practice model, different interaction styles optimising family decision making are described (directing, teaching, collaborating and supporting interaction) (see figure 2). ${ }^{66}$

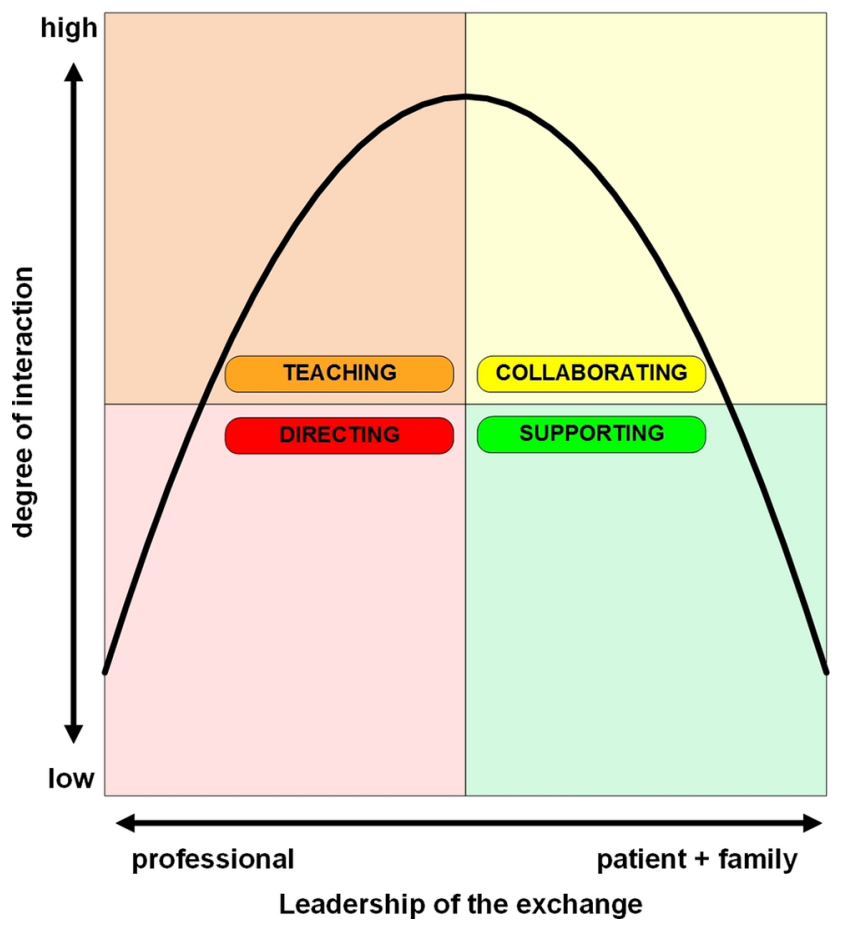

Figure 2 Decision-making model. Reprinted with permission from Feldman et al. ${ }^{66}$ 


\begin{tabular}{ll}
\hline Table 1 Participating centres & \\
\hline Intervention centres & Control centres \\
\hline $\begin{array}{l}\text { Hoogstraat Rehabilitation } \\
\text { (Utrecht) }\end{array}$ & $\begin{array}{l}\text { Adelante Rehabilitation } \\
\text { (Hoensbroek) }\end{array}$ \\
$\begin{array}{l}\text { Revant Rehabilitation Centre } \\
\text { (Breda) }\end{array}$ & Heliomare (Wijk aan Zee) \\
$\begin{array}{l}\text { University Medical Centre } \\
\text { Groningen Beatrixoord } \\
\text { (Haren) }\end{array}$ & $\begin{array}{l}\text { Rehabilitation Centre Merem/ } \\
\text { Roessingh Rehabilitation } \\
\text { (Enschede) }\end{array}$ \\
& St Maartenskliniek (Nijmegen) \\
& $\begin{array}{l}\text { Rijndam Rehabilitation } \\
\text { (Rotterdam) }\end{array}$ \\
& $\begin{array}{l}\text { Reade Rehabilitation } \\
\text { (Amsterdam) }\end{array}$ \\
& $\begin{array}{l}\text { Rehabilitation Friesland } \\
\text { (Beetsterzwaag) }\end{array}$ \\
& Vogellanden Centre for \\
& Rehabilitation (Zwolle) \\
\hline
\end{tabular}

\section{Determinants}

Various psychological (eg, neuroticism, depression and purpose in life $)^{1616368}$ and environmental (eg, family relationships and functioning, social support, emotional and practical support $)^{869-71}$ variables have been identified as determinants of self-efficacy and participation. However, it is not clear if these variables measured during early inpatient rehabilitation may predict long-term empowerment outcomes.

\section{METHODS AND ANALYSIS}

\section{Study design and setting}

A multicentre prospective cohort study will be conducted among patients with leg amputation, acquired brain injury or spinal cord injury who have been admitted as inpatients at a rehabilitation centre and their significant others. The study will be conducted in 12 out of a total of 22 rehabilitation centres in the Netherlands, subdivided into intervention centres where FGG will be implemented and control centres with regular care (see table 1). Patients decide who will be allocated as their significant other ( $\geq 18$ years with a close relationship to the patient), and according to their goals and action plan they decide together which individuals of their social network they want to invite. Eligibility of the participants is screened with the inclusion and exclusion criteria (see box 1). A process evaluation will be conducted to monitor the fidelity of the implementation of the FGC and possible influencing factors affecting the outcomes.

\section{Study procedure}

The study is divided into two parts, which will be introduced separately to patient-significant other couples: the cohort study and the FGC intervention. In the first week after admittance, inclusion and exclusion criteria
Box 1 Inclusion and exclusion criteria for the cohort study

Inclusion criteria

- Recent onset of leg amputation, acquired brain injury or spinal cord injury (patient).

- Expected stay in the rehabilitation centre: at least 4 weeks (patient).

- At least 18 years old (patient and significant other).

Exclusion criteria based on clinical judgement

- Full recovery or nearly full recovery of the patient is expected (patient).

Discharge home: not expected (patient).

- Limited life expectancy (patient).

- High degree of cognitive or intellectual problems (unreliable measurements) (patient).

- Patient has no significant other (patient).

- No informed consent (patient and significant other).

are checked, and information letters about the cohort study and informed consent forms are handed out to patients and significant others by the physiatrist. All included patients and significant others will complete the questionnaires four times: shortly after admission to the clinic (T0), shortly before clinical discharge (T1), and 3 months (T2) and 6 months (T3) after clinical discharge. In the intervention centres, participants will be included in the FGC intervention, based on their level of self-efficacy measured with the Self-Efficacy Scale ${ }^{72} 73$ (see figure 3). It is expected that the FGC intervention will be less effective in individuals who already possess an above-average self-efficacy at admission. Couples in which both the patient and significant other score above average $(\geq 47)$ on the Self-Efficacy Scale ${ }^{7273}$ and all couples in the control centres will participate only in the cohort study and will receive regular rehabilitation care from multidisciplinary professionals (see figure 3 ). This also includes conventional psychosocial support from the social worker (giving diagnosis-specific information and consequences in daily living, involvement in goal setting, support caregivers, community services advice and so on).

Couples in which the patient and/or significant other score below average $(\leq 46)$ will be invited by the social worker for a FGC. Within this cohort, a controlled trial is executed to evaluate the effects of the FGC in addition to regular social work support. A second informed consent for admittance to the FGC will be obtained.

\section{Intervention}

FGC intervention

The FGC intervention is an approach starting at clinical admittance, supporting both patient and social network through the phase of being discharged to home, and continues to following up until the outpatient rehabilitation period is finalised. In this time span there are three fixed meetings (at clinical discharge, and 1.5 and 3 months after discharge) and in between social work contacts with different accents (see table 2). The first 


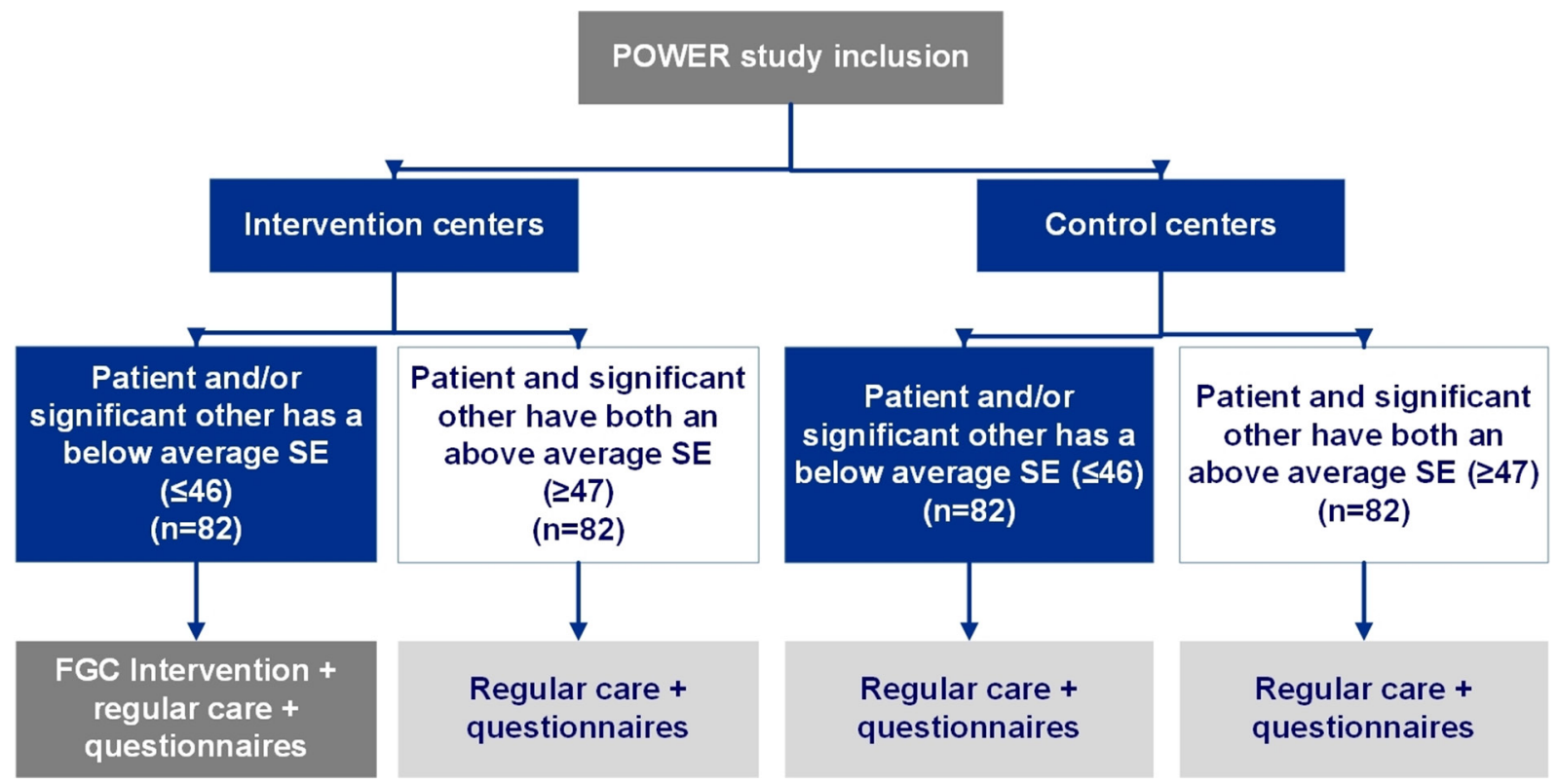

Figure 3 Allocation of participants. FGC, family group conference; SE, self-efficacy.

meeting is a preparatory meeting, explaining the concept of FGC to the patient, significant other and family. The second meeting is the actual FGC in which the patient, significant other and their social network reflect on their goals when being at home, and the support needed to make these goals achievable. They discuss and compose a concrete plan to participate in daily activities that correspond to their aims. The last meeting is to evaluate the achievements of the goals and plans made. All FGC meetings are part of the rehabilitation existing budgets concerning social care, which in case of success make the implementation more straightforward. Some adaptations have been made to translate the original FGC model originated in child care to an adult population in the medical rehabilitation setting. The most important key elements will be adopted, such as the family-driven approach, focus on decision making, the involvement of a wider network and drawing up an action plan. Other key elements as 'independent coordinator' and 'private time' required adaptations more suitable and appropriate for the adult population.

Instead of having an independent coordinator setting up the FGC, more responsibility is given to the adult participants themselves, where a representative of the family (family coordinator) is appointed to take account of the FGC coordination activating family members, fixing time and place, and so on, all in close collaboration with the social worker. This dyadic relationship between the family member and the professional is based on equality and has the potential to increase ownership of the FGC.

The opportunity of private family time without professionals being present (one of the core principles of FGC) is introduced and often already part of the normal interaction and collaboration between family members (sometimes in self-organised family meetings, WhatsApp groups, online applications used to set up an action plan and so on).

\section{Workshop and coaching}

All social workers in the intervention rehabilitation centres will be trained once in a 1-day workshop to introduce the FGC manual with the decision-making tools and the theory behind the decision-making process. From each intervention centre, a social worker representative is appointed, who will be in close contact with the researchers concerning the implementation of FGC in their centre and among their colleague-social workers. Return meetings will be organised to refresh the learnt skills and to allow exchange of experiences.

All social workers will receive coaching by an independent coach experienced in family-centred rehabilitation as well as coaching groups by giving advice regarding the decision-making interaction with the patient and their family. For this purpose, meetings will be videotaped and observed after given informed consent.

\section{FGC manual}

The social worker systematically uses and introduces several tools using a detailed manual and protocol for each FGC meeting and in between meeting describing the decision-making tools in detail, such as (1) a social network analysis: gaining insight of the support system and encouraging participation of both the patient and the significant other; (2) an action plan: setting up goals concerning daily activities and the help needed to attain them; and (3) a Caregiver Strain Index: making an inventory of burden experienced by the significant other (see table 2). The tools are designed to increase motivation and equal partnership, and promote participation and self-efficacy. ${ }^{74}$ 
Table 2 Decision-making tools

What+When
Social work contact with couple
(0-2 weeks after clinical admittance
until end of clinical admittance)

Preparatory meeting

Meeting 1 with family,

couple+social worker (at clinical discharge)
Social work contact with couple+family coordinator (end of clinical admittance until 1.5 months after clinical discharge)

\section{Family group conference}

Meeting 2 with family,

couple+social worker (1.5 months after clinical discharge)

Social work contact with
couple+family coordinator (1.5-3 months
after clinical discharge)

Evaluation meeting Meeting 3 with family, couple+social worker (3 months after clinical discharge)

\section{Action}

Inform patient/significant other about allocation family group conference in multidisciplinary rehabilitation care

Inventory Caregiver Strain Index, significant Caregiver Strain Index ${ }^{96}$ other

Inventory of Social Support Network Social network analyses ${ }^{110}$

Inventory of attendees present at family group conference

Nominating 'family coordinator' by social network

Assess level of empowerment of couples

Insight in goal attainment, participation in daily activities

Discuss level of social network support Activation of social network Introducing action plan Inform 'family coordinator' Assess level of empowerment of couples

\section{Tool}

Overview disciplines/programmes

Social network analyses

Preparing 'family coordinator'

Empowerment tool (self-composed)

Goal attainment scale 'the entire live ${ }^{, 111}$

Utrecht Scale for Evaluation of Rehabilitation - Participation $(\text { USER-P) })^{79}$

Social network analyses ${ }^{110}$

Apps, phone, other

Action plan ${ }^{112}$

Manual 'family coordinator'

Empowerment tool (self-composed)

Manual 'family coordinator'

Evaluating deployed actions

Assess level of empowerment of couples

Setting up action plan

Assess level of empowerment of couples

Empowerment tool (self-composed) Action plan ${ }^{112}$

Empowerment tool (self-composed)

Evaluation of deployed actions, 'family coordinator'

Evaluation of execution of action plan Assess level of empowerment of couples Insight in goal attainment, participation in daily activities

Action plan ${ }^{112}$

Empowerment tool (self-composed)

Goal attainment scale 'the entire live,111

Utrecht Scale for Evaluation of Rehabilitation - Participation $\left(\right.$ USER-P) ${ }^{79}$

Assess level of empowerment of couples
Manual 'family coordinator'

\section{Sample size}

Sample size is calculated based on analysis of covariance in a parallel group design. ${ }^{75}$ Due to the absence of a formal quantitative evaluation of the FGC to date, results from a systematic review of the effectiveness of behaviour change techniques in order to increase self-efficacy ${ }^{76}$ are used to estimate the effect size. ${ }^{77}$ A moderate effect size of 0.5 is expected. With this expected effect size, a pretest and a post-test 3 months postintervention, correction for dependency in the clusters ( $\mathrm{n}=38$ social workers), an intraclass correlation of 0.05 , a two-sided alpha value of 0.05 and a power of $80 \%$, the required total sample size is $n=150$. The total sample size will be 164 when taking into account a $10 \%$ dropout of participant couples during the study. Therefore 82 couples with a below-average self-efficacy will receive FGCs in the intervention group and 82 couples with a below-average self-efficacy will receive regular care in the control group.

For the identification of predictors of self-efficacy and participation, we additionally include participant couples in the intervention and control centres with above-average self-efficacy scores. An equal number of participant couples will be recruited in these groups as in the two mentioned groups (82 each). Therefore, the total sample 
size will be $n=328$, which is estimated to be achievable based on known patient flows, recruitment rates and study retention rates.

\section{Study outcome measures}

An overview of all instruments that are used at different time points in the study is shown in table 3 . The majority of the instruments have validated scales. Self-efficacy ${ }^{72} 7378$ and participation ${ }^{79-83}$ are the primary outcomes. The secondary outcomes are distress,${ }^{84-87}$ life satisfaction, ${ }^{88-91}$ experienced continuity of care ${ }^{92}{ }^{93}$ care empowerment, ${ }^{94} 95$ assistance from the social network (patient only), ${ }^{9}$ provided assistance (significant other only), ${ }^{9}$ burden of care (significant other only ${ }^{96-100}$ and caregiver mastery (significant other only). ${ }^{101} 102$

Additional determinants will be measured: demographic factors, functional status factors (independence in self-care and mobility, patient only), cognition impairment (acquired brain injury, patient only) and injury-specific information (patient only). Finally, an assessment battery of concepts which are identified as predictive for long-term adjustment problems will be used in order to identify predictors of long-term (up to 6 months) self-efficacy and participation. ${ }^{1861-6368-70}$

\section{Process evaluation}

A process evaluation is an integral part of the study and will be conducted in each of the participating rehabilitation centres according to the Medical Research Council framework. ${ }^{103}$ This framework assesses fidelity and quality of implementation, clarifies causal mechanisms and identifies contextual factors associated with variation in outcomes. ${ }^{104}$ This indepth information regarding the fidelity and feasibility of the implementation of FGCs can be used to optimise the design of future interventions and possible nationwide implementation if effectivity is determined.

In order to conduct this trial in a uniform way, compliance will be assessed in the intervention centres, evaluating which components of the FGCs are implemented and delivered. A detailed manual and protocol for each FGC have been written describing the decision-making tools. Social workers will administer all used decision-making tools with a self-reported checklist right after each meeting (see table 2). Further compliance will be assessed monthly by administering the delivered and attended FGCs. Researchers will monitor the study, monthly evaluating the checklists, visiting the social workers and research assistants, and attending sessions of the FGCs at all participating centres.

Semistructured interviews will be held with social workers $(n=15)$ concerning the barriers and the facilitators implementing FGCs. Case studies ( $\mathrm{n}=8$ unique patient cases) will take place gathering information on both patients, significant others, members of social network and professionals regarding their satisfaction with the FGC, the decision-making process, and made and achieved action plans and goals.
Qualitative data will be written as verbatim, coded and analysed using content analyses ${ }^{105}$ using the qualitative analysis software MAXQDA. ${ }^{106}$

\section{Statistical methods and data management}

First, multivariate regression analysis will identify predictors of long-term self-efficacy and participation. Nesting of the data and participation in the intervention will be accounted for. Multilevel random coefficient analysis of covariance comparing preintervention and postintervention scores on the primary outcomes will be used to analyse the effectiveness of the FGCs. Multilevel analysis allows for correction due to nested data and to inclusion of persons with partly missing data in the analyses. Data will be analysed according to the intention-to-treat principle. Per-protocol analyses will be performed in order to explore which elements of the FGC can be considered effective and for whom. SPSS statistical program for Windows will be used, and effects with a $\mathrm{P}$ value below 0.05 (two-tailed) will be regarded as significant.

Data will be gathered by two researchers (CFH, EWMS) supervised by the research team closely collaborating. Data and backup information will be stored on a secured computer file.

\section{Ethics and dissemination}

All participating rehabilitation centres have approved the study protocol.

The results will be published in peer-reviewed journals and presented in local, national and international conferences. The protocol for the multicentre controlled trial was entered in the Dutch trial register (NTR5742).

\section{DISCUSSION}

This study will be the first multicentre controlled trial evaluating the effectiveness and the implementation of FGCs among the adult population and their significant others in the field of rehabilitation medicine. With this study we expect to gain knowledge on the effectiveness of implementing FGCs in rehabilitation care. We can identify predictors of self-efficacy and participation up to 6 months after clinical discharge. This enables development of a screening on risk factors in an early stage of rehabilitation treatment. Also, a structured and theoretically based FGC will be developed, tested and evaluated in different Dutch rehabilitation centres.

Several aspects of the study will contribute to its strength:

- Focusing on the patient and significant other simultaneously is relatively new and, based on former research, ${ }^{107}$ expected to be more effective than focusing solely on the patient.

- The social network of the patient and the significant other will become more closely involved in the rehabilitation process in an early stage of rehabilitation. This new aspect of rehabilitation care seems promising in 
Table 3 Measurements for patients and significant other

\begin{tabular}{|c|c|c|c|c|c|}
\hline Outcome measures & Instruments & TO & T1 & T2 & T3 \\
\hline \multicolumn{6}{|c|}{ Primary outcome measures } \\
\hline Self-efficacy & University of Washington Self-Efficacy Scale short form ${ }^{78}$ & $\mathrm{X}$ & $\mathrm{X}$ & $\mathrm{X}$ & $\mathrm{X}$ \\
\hline Participation (preinjury) & $\begin{array}{l}\text { Utrecht Scale for Evaluation of Rehabilitation- } \\
\text { Participation }\end{array}$ & $x$ & $x^{C}$ & $x$ & $x$ \\
\hline
\end{tabular}

Secondary outcome measures

\begin{tabular}{|c|c|c|c|c|c|}
\hline Distress & Hospital Anxiety and Depression Scale 8485 & $\mathrm{X}$ & $X$ & $\mathrm{X}$ & $\mathrm{X}$ \\
\hline Life satisfaction & Life Satisfaction (two questions) ${ }^{88} 89$ & $\mathrm{X}$ & $\mathrm{X}$ & $\mathrm{X}$ & $\mathrm{X}$ \\
\hline Experienced continuity of care & $\begin{array}{l}\text { Consumer Quality index Brain Injury (collaboration } \\
\text { subscale) }\end{array}$ & & & & $x$ \\
\hline Care empowerment & Patient Assessment of Chronic Illness Care (selection) ${ }^{9495}$ & & & & $\mathrm{X}$ \\
\hline $\begin{array}{l}\text { Assistance from social } \\
\text { network }\end{array}$ & Adapted version of existing list of activities ${ }^{9}$ & & & & $X^{P}$ \\
\hline Burden of care & Caregiver Strain Index ${ }^{96}$ & & & $x^{C}$ & $X^{C}$ \\
\hline Burden of care & Self-Rated Burden Scale ${ }^{97}$ & $X^{C}$ & $X^{C}$ & $X^{C}$ & $X^{C}$ \\
\hline Caregiver mastery & Caregiver Mastery Scale ${ }^{101}$ & & & & $X^{C}$ \\
\hline
\end{tabular}

Determinants

$\begin{array}{ll}\text { Demographic factors } & \text { Age, gender, ethnicity, family income, level of education, }{ }^{113} \mathrm{X} \quad \mathrm{X}^{2} \\ \text { marital status, family composition }\end{array}$

Functional status

Utrecht Scale for Evaluation of Rehabilitation (self-care and $X^{P} \quad X^{P}$ mobility subscales) ${ }^{114}$

Cognition impairment

Injury-specific information

Montreal Cognitive Assessment ${ }^{115}$ (ABI)

$X^{P}$

Cause of injury; comorbidity; American Spinal Injury

Association Impairment Scale ${ }^{116}$; Special Interest Group

on Amputation Medicine-Working Group Amputation and

Prosthetics score ${ }^{117118}$ (amputation); Bamford/Oxford

Classification ${ }^{119}$; Stichting Afasie Nederland schaal (Dutch

Aphasia Foundation Scale, SAN) ${ }^{120}$; National Institutes of

Health Stroke Scale ${ }^{121}$ (Acquired brain injury)

\begin{tabular}{|c|c|c|c|c|c|}
\hline Self-efficacy & Self-Efficacy Scale (General Competence Scale) ${ }^{72} 73$ & $x$ & & & \\
\hline $\begin{array}{l}\text { Personality characteristic, } \\
\text { neuroticism }\end{array}$ & $\begin{array}{l}\text { Eysenck Personality Questionnaire Revised Short Scale } \\
\text { (neuroticism subscale) }^{122123}\end{array}$ & $\mathrm{X}$ & & & \\
\hline Passive coping & Utrecht Coping List (passive coping subscale) ${ }^{125126}$ & $\mathrm{X}$ & & & \\
\hline Appraisal & Appraisal of Life Events (treat and loss subscales) ${ }^{127}$ & $X$ & & & \\
\hline Purpose in life & Purpose in Life Short Form ${ }^{129} 130$ & $\mathrm{X}$ & & & \\
\hline Family functioning & $\begin{array}{l}\text { Family Assessment Device (subscale general } \\
\text { functioning) }\end{array}$ & $\mathrm{X}$ & $\mathrm{X}$ & $\mathrm{X}$ & $\mathrm{X}$ \\
\hline Fatigue, general health, mood & Numeric Rating Scale & $\mathrm{X}$ & $\mathrm{X}$ & $\mathrm{X}$ & $x$ \\
\hline Existing social network & Self-composed & $X$ & & & \\
\hline
\end{tabular}

TO: shortly after admission of the patient in the rehabilitation centre; $\mathrm{T} 1$ : shortly before clinical discharge of the patient from the rehabilitation centre; T2: 3 months after discharge; T3: 6 months after discharge.

$\mathrm{X}$, patient and informal caregiver; $\mathrm{X}^{\mathrm{P}}$, only patient; $\mathrm{X}^{\mathrm{C}}$, only informal caregiver.

ABI, Acquired brain injury; ALCOS-12= Algemene Competentieschaal 12 (General Competence Scale 12 questions); LS2, Life Satisfaction (2 questions). 
the recovery and adaptation process of the patient ${ }^{70}$ and in moderating caregiver distress. ${ }^{108}$

- Conducting FGCs requires a paradigm shift of patient/ significant other but also the social workers, especially on the domain of decision making. Social workers who are often proactive in their counselling must now withhold themselves more in order to enlarge the empowerment of the patient, significant other and their network. Implementation of the FGCs will gather insight into these decision-making processes and possible barriers and facilitators acquiring this paradigm shift.

- The results of the study will be representative of a broad range of rehabilitation patients in three diagnostic groups (acquired brain injury, spinal cord injury and leg amputation).

- With the identification of predictors of self-efficacy and participation, a more scientifically based selection tool can be developed that may help in deciding to deploy FGCs in the future. Furthermore, in the intervention group, subgroups may be distinguished based on the effectiveness of the FGC.

- Implementing and evaluating the FGC in a structured and theoretically grounded way is intended to enlarge the evidence in social work in medical rehabilitation care.

- The implementation, monitored by a process evaluation, will clarify causal mechanisms and gain knowledge about possible influencing barriers and facilitators, making it possible to optimise the design of future interventions.

- The longitudinal design of the study offers the possibility to explore the effectiveness of the FGC after a follow-up period of 6 months.

The following are some limitations of this study:

- Due to the subjective nature of most variables, self-administered questionnaires will be used. Results can be biased due to socially desirable answering; however, the instructions clearly note that there are no right or wrong answers and that participants should complete the questionnaire independently. A research assistant will provide assistance when needed.

- Aiming to develop a feasible intervention, the FGC was designed keeping in mind that it should fit in the current organisation and financing of rehabilitation care. Variables to be considered were the type of population (adults), duration of clinical admittance and outpatient rehabilitation, time until FGC referral and time needed for family to set up a plan and so on. In some respect, this limits the possibilities and probably the effectiveness of the FGCs; for example, the timing of the meetings is fixed due to financial restrictions, and there will not be an independent coordinator (a family coordinator instead) who will support the participating family, which is part of the original FGC model in child care. ${ }^{31-33}$ However, it is evident that the design has to be adapted to the adult population and be time and cost-effective in order to have any prospects for future implementation in routine care.

- The study is not a randomised controlled trial, which is the preferred study design to examine intervention effects. In a situation of random allocation of FGCs within social work teams, it cannot be ruled out that the social workers also implement (aspects of) the FGCs in patients excluded from the intervention. Therefore, admittance in either a control or intervention centre, instead of random allocation, determines if the patients will receive the FGC. Patients and caregivers who do not participate in the FGC will receive 'regular care', which may vary between rehabilitation centres. Differences will be monitored.

- Although it is expected that the intervention could be beneficial for all patients and their social network, in this study we decided to focus on the group that we expect (based on previous findings) has the most potential to benefit from it. In former research, a relationship between self-efficacy and participation was found. ${ }^{63}$ Based on these findings it is assumed that the intervention (which is aimed to improve self-efficacy and participation) will be less effective for couples with a relatively existing high level of self-efficacy at onset. Accordingly, only couples with a relatively low level of self-efficacy at onset will follow the intervention.

In summary, we have described a study evaluating a novel FGC intervention for rehabilitation patients and their significant others that is aimed to enlarge their self-efficacy, participation and decision making. It has the potential to detect efficacy and explain the influencing determinants to improve future rehabilitation care.

Acknowledgements We would like to thank D Ruitenbeek from Korter Maar Krachtig (patient organisation, amputation), J Dekkers from the Dwarslaesie Organisatie Nederland (patient association, spinal cord injury) and E van Gorp from Hersenletsel.nl (patient organisation, acquired brain injury), the rehabilitation physicians association VRA, E Witteveen (senior researcher at the University of Applied Science, Center of Excellence of Social Innovation), E Radersma (caregiver representative), J Keetbaas (rehabilitation social worker of Hoogstraat Rehabilitation), I van de Port (programme manager of Revant Rehabilitation Centre) and T van Diemen (PhD candidate, empowerment study 'SELF-SCl' of the University of Groningen) for their participation and input. This research collaboration is only possible with the involvement of the participating rehabilitation centres and their research assistants, social workers, physiatrists, organisations and management: Revant Rehabilitation Centre (Breda), UMCG Rehabilitation Centre Beatrixoord (Haren), Roessingh Rehabilitation (Enschede), Hoogstraat Rehabilitation (Utrecht), Adelante Rehabilitation (Hoensbroek), Heliomare (Wijk aan Zee), Reade Rehabilitation (Amsterdam), St Maartenskliniek (Nijmegen), Rijndam Rehabilitation (Rotterdam), Rehabilitation Centre Merem/De Trappenberg (Huizen), Rehabilitation Friesland (Beetsterzwaag) and Vogellanden Centre for Rehabilitation (Zwolle).

Contributors CFH and EWMS developed the first version of the manuscript, in collaboration with JMAV-M, MWMP and MK. JMAV-M, MWMP and MK supervised the writing process and gave critical comments on several drafts of the manuscript. JMAV-M, MWMP and MK provided statistical and methodological advice. CFH and EWMS wrote the final version of the manuscript.

Funding This study is financially supported by ZonMw, the Netherlands Organisation for Health Research and Development, Fonds Nuts Ohra and Revalidatiefonds, grant number: 630000003.

Competing interests None declared.

Patient consent Obtained. 
Ethics approval The Medical Ethics Committee of the University Medical Center Utrecht reviewed the study protocol (number 15-617/C) and decided that the present study does not fall under the scope of the Dutch Medical Research Involving Human Subjects Act (WMO).

Provenance and peer review Not commissioned; externally peer reviewed. Open Access This is an Open Access article distributed in accordance with the Creative Commons Attribution Non Commercial (CC BY-NC 4.0) license, which permits others to distribute, remix, adapt, build upon this work non-commercially, and license their derivative works on different terms, provided the original work is properly cited and the use is non-commercial. See: http://creativecommons.org/ licenses/by-nc/4.0/

(c) Article author(s) (or their employer(s) unless otherwise stated in the text of the article) 2018. All rights reserved. No commercial use is permitted unless otherwise expressly granted.

\section{REFERENCES}

1. Carpenter C, Forwell SJ, Jongbloed LE, et al. Community participation after spinal cord injury. Arch Phys Med Rehabil 2007;88:427-33.

2. Goverover $\mathrm{Y}$, Genova $\mathrm{H}$, Smith $\mathrm{A}$, et al. Changes in activity participation following traumatic brain injury. Neuropsychol Rehabil 2017;27:472-85.

3. Craig A, Tran Y, Middleton J. Psychological morbidity and spinal cord injury: a systematic review. Spinal Cord 2009;47:108-14.

4. Post MW, van Leeuwen CM. Psychosocial issues in spinal cord injury: a review. Spinal Cord 2012;50:382-9.

5. Sales E. Family burden and quality of life. Qual Life Res 2003;12(Suppl 1):33-41.

6. Schulz R, Beach SR. Caregiving as a risk factor for mortality. JAMA 1999;282:2215-9.

7. Rigby H, Gubitz G, Phillips S. A systematic review of caregiver burden following stroke. Int J Stroke 2009;4:285-92.

8. Teasell RW, Foley NC, Bhogal SK, et al. An evidence-based review of stroke rehabilitation. Top Stroke Rehabil 2003;10:29-58.

9. Post MW, Bloemen J, de Witte LP. Burden of support for partners of persons with spinal cord injuries. Spinal Cord 2005;43:311-9.

10. Visser-Meily JMA, Witteveen E, Wilken JP. Inventarisatielijst mantelzorg [Inventarisation list informal caregiver]. Utrecht 2012.

11. McKevitt C, Redfern J, Mold F, et al. Qualitative studies of stroke: a systematic review. Stroke 2004;35:1499-505.

12. Visser-Meily JM, Post MW, Schepers VP, et al. Spouses' satisfaction with caregiver support in stroke rehabilitation. Scand J Caring Sci 2005; 19:310-6.

13. Loupis YM, Faux SG. Family conferences in stroke rehabilitation: a literature review. J Stroke Cerebrovasc Dis 2013;22:883-93.

14. Bloemen-Vrencken JH, de Witte LP, Post MW, et al. Comparison of two Dutch follow-up care models for spinal cord-injured patients and their impact on health problems, re-admissions and quality of care. Clin Rehabil 2007:21:997-1006.

15. Bamm EL, Rosenbaum P. Family-centered theory: origins, development, barriers, and supports to implementation in rehabilitation medicine. Arch Phys Med Rehabil 2008;89:1618-24

16. Fronek P. Insights from the family conference: observations in rehabilitation. Aust Soc Work 2005:58:395-406.

17. Reed M, Harding KE. Do family meetings improve measurable outcomes for patients, carers, or health systems? A systematic review. Aust Soc Work 2015;68:244-58.

18. Hudson $\mathrm{P}$, Thomas $\mathrm{T}$, Quinn $\mathrm{K}$, et al. Family meetings in palliative care: are they effective? Palliat Med 2009;23:150-7.

19. Crisp R. Consumer participation in rehabilitation: an unresolved issue. Aust Soc Work 1989;42:39-42.

20. Efraimsson E, Sandman PO, Hydén LC, et al. Discharge planning: "fooling ourselves?"--patient participation in conferences. J Clin Nurs 2004;13:562-70.

21. MacKean GL, Thurston WE, Scott CM. Bridging the divide between families and health professionals' perspectives on family-centred care. Health Expect 2005;8:74-85.

22. Kovacs PJ, Bellin MH, Fauri DP. Family-centered care: a resource for social work in end-of-life and palliative care. J Soc Work End Life Palliat Care 2006;2:13-27.

23. Metze RN, Kwekkeboom RH, Abma TA. 'You don't show everyone your weakness': Older adults' views on using family group conferencing to regain control and autonomy. J Aging Stud 2015;34:57-67.
24. Joling KJ, van Marwijk HW, Smit F, et al. Does a family meetings intervention prevent depression and anxiety in family caregivers of dementia patients? A randomized trial. PLoS One 2012;7:e30936.

25. Joling KJ, van Marwijk HW, van der Horst HE, et al. Effectiveness of family meetings for family caregivers on delaying time to nursing home placement of dementia patients: a randomized trial. PLOS One 2012;7:e42145.

26. Visser-Meily A, Post M, Gorter JW, et al. Rehabilitation of stroke patients needs a family-centred approach. Disabil Rehabil 2006;28:1557-61.

27. Creasy KR, Lutz BJ, Young ME, et al. Clinical implications of familycentered care in stroke rehabilitation. Rehabil Nurs 2015;40:349-59.

28. Monaghan J, Channell K, McDowell D, et al. Improving patient and carer communication, multidisciplinary team working and goalsetting in stroke rehabilitation. Clin Rehabil 2005;19:194-9.

29. New Zealand. Children, young persons, and their families act, 1989. Annu Rev Popul Law 1989;16:513-5.

30. Merkel-Holguin L, Marcynyszyn LA. The complexity of fidelity in measuring system change: the case of family group decision making. Br J Soc Work 2015;45:724-36.

31. Merkel-Holguin L. Sharing power with the people: family group conferencing as a democratic experiment. J Sociol Soc Welf 2004:31:155-73.

32. Pennell J, Burford G. Family group decision making: protecting children and women. Child Welfare 2000;79:131-58.

33. Burford G, Pennell J, Macleod S. Manual for coordinators and communities: the organization and practice of family group decision making: Memorial University of Newfoundland School of Social Work, 1995

34. Lupton C. User empowerment or family self-reliance? The family group conference model. Br J Soc Work 1998;28:107-28.

35. Aujoulat I, d'Hoore W, Deccache A. Patient empowerment in theory and practice: polysemy or cacophony? Patient Educ Couns 2007;66:13-20

36. de Jong G, Schout G. Family group conferences in public mental health care: an exploration of opportunities. Int J Ment Health Nurs 2011;20:63-74

37. Jackson S, Morris K. Family group conferences: user empowerment or family self-reliance?--a development from Lupton. $\mathrm{Br} J$ Soc Work 1999;29:621-30.

38. Asscher JJ, Dijkstra S, Stams GJ, et al. Family group conferencing in youth care: characteristics of the decision making model, implementation and effectiveness of the Family Group (FG) plans. BMC Public Health 2014:14:154

39. Maluccio AN, Ainsworth F, Thoburn J. Child welfare outcome research in the United States, the United Kingdom, and Australia: Child Welfare League of America, 2000.

40. Sundell K, Vinnerljung B. Outcomes of family group conferencing in Sweden. A 3-year follow-up. Child Abuse Negl 2004;28:267-87.

41. Huntsman L. Family group conferencing in a child welfare context a review of the literature. New South Wales: Centre for Parenting \& Research, Funding \& Business Analysis Division, NSW Department of Community Services, 2006. www. dhcs. act. gov. au/_data/ assets/pdf_file/0006/48750/Literature_review_on_family_Gro up_ Conferencing. pdf

42. Onrust SA, Romijn G, de Beer Y. Family group conferences within the integrated care system for young people with ID: a controlled study of effects and costs. BMC Health Serv Res 2015;15:392.

43. Pennell J, Edwards M, Burford G. Expedited family group engagement and child permanency. Child Youth Serv Rev 2010;32:1012-9.

44. Frain MP, Bishop M, Tschopp MK. Empowerment variables as predictors of outcomes in rehabilitation. $J$ Rehabil 2009;75:27.

45. Fumagalli LP, Radaelli G, Lettieri E, et al. Patient empowerment and its neighbours: clarifying the boundaries and their mutual relationships. Health Policy 2015;119:384-94.

46. Wallerstein N. What is the evidence on effectiveness of empowerment to improve health? Copenhagen Denmark: World Health Organization [WHO] Regional Office for Europe Health Evidence Network, 2006

47. Rappaport J. Terms of empowerment/exemplars of prevention: toward a theory for community psychology. Am J Community Psychol 1987;15:121-48.

48. Zimmerman MA, Warschausky S. Empowerment theory for rehabilitation research: Conceptual and methodological issues. Rehabil Psychol 1998;43:3-16.

49. Christens BD. Toward relational empowerment. Am J Community Psychol 2012;50:114-28.

50. Riger S. What's wrong with empowerment. Am J Community Psychol 1993;21:279-92.

51. Rowlands J. Empowerment examined. Dev Pract 1995;5:101-7. 
52. Van Regenmortel T. Zwanger van empowerment [Pregnant with empowerment]. Lectoral speech. Tilburg: University of applied sciences, 2008.

53. Metze RN, Kwekkeboom RH, Abma TA. The potential of Family Group Conferencing for the resilience and relational autonomy of older adults. J Aging Stud 2015;34:68-81.

54. Metze RN. Independence or interdependence, FGC among older adults. dissertation, 2016.

55. Fisher MI, Howell D. The power of empowerment: An ICF-based model to improve self-efficacy and upper extremity function of survivors of breast cancer. Rehabil Oncol 2010;28:19-25.

56. Israel BA, Checkoway B, Schulz A, et al. Health education and community empowerment: conceptualizing and measuring perceptions of individual, organizational, and community control. Health Educ Q 1994;21:149-70.

57. Bandura A. Self-efficacy: toward a unifying theory of behavioral change. Adv Behavin Res Ther 1978;1:139-61.

58. Ozer EM, Bandura A. Mechanisms governing empowerment effects: a self-efficacy analysis. J Pers Soc Psychol 1990;58:472-86.

59. Bandura A. Social foundations of thought and action: The health psychology reader, 2002:94-106.

60. World Health Organization. International classification of functioning, disability and health. ICF, Geneva: World Health Organization, 2001.

61. Korpershoek C, van der Bijl J, Hafsteinsdóttir TB. Self-efficacy and its influence on recovery of patients with stroke: a systematic review. J Adv Nurs 2011;67:1876-94.

62. Cijsouw A, Adriaansen JJ, Tepper M, et al. Associations between disability-management self-efficacy, participation and life satisfaction in people with long-standing spinal cord injury. Spinal Cord 2017:55:47-51.

63. Peter C, Müller R, Post MW, et al. Psychological resources, appraisals, and coping and their relationship to participation in spinal cord injury: a path analysis. Arch Phys Med Rehabil 2014;95:1662-71.

64. Nogales-González C, Romero-Moreno R, Losada A, et al. Moderating effect of self-efficacy on the relation between behavior problems in persons with dementia and the distress they cause in caregivers. Aging Ment Health 2015;19:1022-30.

65. van den Heuvel ET, de Witte LP, Schure LM, et al. Risk factors for burn-out in caregivers of stroke patients, and possibilities for intervention. Clin Rehabil 2001;15:669-77.

66. Feldman HM, Ploof D, Cohen WI. Physician-family partnerships: the adaptive practice model. J Dev Behav Pediatr 1999;20:111-6.

67. Rauktis ME, Bishop-Fitzpatrick L, Jung N, et al. Family group decision making: measuring fidelity to practice principles in public child welfare. Child Youth Serv Rev 2013;35:287-95.

68. Jones F, Riazi A. Self-efficacy and self-management after stroke: a systematic review. Disabil Rehabil 2011;33:797-810.

69. Barclay L, McDonald R, Lentin P. Social and community participation following spinal cord injury: a critical review. Int $J$ Rehabil Res 2015;38:1-19.

70. Müller R, Peter C, Cieza A, et al. The role of social support and social skills in people with spinal cord injury--a systematic review of the literature. Spinal Cord 2012;50:94-106.

71. Whiteneck G, Meade MA, Dijkers M, et al. Environmental factors and their role in participation and life satisfaction after spinal cord injury. Arch Phys Med Rehabil 2004;85:1793-803.

72. Bosscher RJ, Smit JH, Kempen G. Algemene competentieverwachtingen bij ouderen [General competence expectations in the elderly]. Ned Tijdschr voor Psychol 1997:52:239-48.

73. Bosscher RJ, Smit JH. Confirmatory factor analysis of the general self-efficacy scale. Behav Res Ther 1998;36:339-43.

74. Elwyn G, Frosch D, Thomson R, et al. Shared decision making: a model for clinical practice. J Gen Intern Med 2012;27:1361-7.

75. Teerenstra S, Eldridge S, Graff M, et al. A simple sample size formula for analysis of covariance in cluster randomized trials. Stat Med 2012;31:2169-78

76. French DP, Olander EK, Chisholm A, et al. Which behaviour change techniques are most effective at increasing older adults' selfefficacy and physical activity behaviour? A systematic review. Ann Behav Med 2014;48:225-34.

77. Cohen LS. Statistical power analysis for the behavioral sciences. Hillsdale, NJ: Erlbaum, 1988.

78. Amtmann D, Bamer AM, Cook KF, et al. University of Washington self-efficacy scale: a new self-efficacy scale for people with disabilities. Arch Phys Med Rehabil 2012;93:1757-65.

79. Post MW, van der Zee $\mathrm{CH}$, Hennink J, et al. Validity of the utrecht scale for evaluation of rehabilitation-participation. Disabil Rehabil 2012;34:478-85.
80. van der Zee $\mathrm{CH}$, Priesterbach AR, van der Dussen L, et al. Reproducibility of three self-report participation measures: The ICF measure of participation and activities screener, the participation scale, and the Utrecht scale for evaluation of rehabilitationparticipation. J Rehabil Med 2010;42:752-7.

81. van der Zee CH, Post MW, Brinkhof MW, et al. Comparison of the Utrecht scale for evaluation of rehabilitation-participation with the icf measure of participation and activities screener and the WHO Disability Assessment Schedule II in persons with spinal cord injury. Arch Phys Med Rehabil 2014;95:87-93.

82. Post MWM, Zee Cvander. Poster 24 validity of three participation questionnaires for use in persons with spinal cord injury. Arch Phys Med Rehabil 2013;94:e20.

83. van der Zee $\mathrm{CH}$, Kap A, Rambaran Mishre R, et al. Responsiveness of four participation measures to changes during and after outpatient rehabilitation. J Rehabil Med 2011;43:1003-9.

84. Zigmond AS, Snaith RP. The hospital anxiety and depression scale. Acta Psychiatr Scand 1983;67:361-70.

85. Spinhoven P, Ormel J, Sloekers PP, et al. A validation study of the Hospital Anxiety and Depression Scale (HADS) in different groups of Dutch subjects. Psychol Med 1997;27:363-70.

86. Woolrich RA, Kennedy P, Tasiemski T. A preliminary psychometric evaluation of the Hospital Anxiety and Depression Scale (HADS) in 963 people living with a spinal cord injury. Psychol Health Med 2006;11:80-90.

87. De Wit L, Putman K, Baert I, et al. Anxiety and depression in the first six months after stroke. A longitudinal multicentre study. Disabil Rehabil 2008;30:1858-66.

88. Post MW, van Leeuwen CM, van Koppenhagen CF, et al. Validity of the Life Satisfaction questions, the life satisfaction questionnaire, and the satisfaction with life scale in persons with spinal cord injury. Arch Phys Med Rehabil 2012;93:1832-7.

89. van Koppenhagen CF, Post MW, van der Woude LH, et al. Recovery of life satisfaction in persons with spinal cord injury during inpatient rehabilitation. Am J Phys Med Rehabil 2009;88:887-95.

90. van Mierlo ML, van Heugten CM, Post M, et al. Life satisfaction post stroke: The role of illness cognitions. J Psychosom Res 2015;79:137-42.

91. van Leeuwen CM, Post MW, van Asbeck FW, et al. Life satisfaction in people with spinal cord injury during the first five years after discharge from inpatient rehabilitation. Disabil Rehabil 2012;34:76-83.

92. Nivel: Nederlands instituut voor onderzoek van de gezondheidszorg [Nivel: Dutch institute for research of health care]. CQ-index CVA [stroke CQ-index] 2015.

93. Berendsen AJ, Groenier KH, de Jong GM, et al. Assessment of patient's experiences across the interface between primary and secondary care: consumer quality index continuum of care. Patient Educ Couns 2009;77:123-7.

94. Glasgow RE, Wagner EH, Schaefer J, et al. Development and validation of the Patient Assessment of Chronic Illness Care (PACIC). Med Care 2005;43:436-44.

95. Vrijhoef HJ, Berbee R, Wagner EH, et al. Quality of integrated chronic care measured by patient survey: identification, selection and application of most appropriate instruments. Health Expect 2009;12:417-29.

96. Robinson BC. Validation of a Caregiver Strain Index. J Gerontol 1983;38:344-8.

97. van Exel NJ, Scholte op Reimer WJ, Brouwer WB, et al. Instruments for assessing the burden of informal caregiving for stroke patients in clinical practice: a comparison of CSI, CRA, SCQ and self-rated burden. Clin Rehabil 2004;18:203-14.

98. Post MW, Festen H, van de Port IG, et al. Reproducibility of the caregiver strain index and the caregiver reaction assessment in partners of stroke patients living in the Dutch community. Clin Rehabil 2007;21:1050-5.

99. Kruithof WJ, Post MW, Visser-Meily JM. Measuring negative and positive caregiving experiences: a psychometric analysis of the caregiver strain index expanded. Clin Rehabil 2015;29:1224-33.

100. Visser-Meily JM, Post MW, Riphagen II, et al. Measures used to assess burden among caregivers of stroke patients: a review. Clin Rehabil 2004;18:601-23.

101. Stewart A, Ware J. Measuring functioning and well-being: the medical outcome study approach. Durham: Duke University Press, 1992.

102. Boele FW, Hoeben W, Hilverda K, et al. Enhancing quality of life and mastery of informal caregivers of high-grade glioma patients: a randomized controlled trial. J Neurooncol 2013;111:303-11.

103. Craig P, Dieppe P, Macintyre S, et al. Developing and evaluating complex interventions: The new medical research council guidance 2008. 
104. Moore G, Audrey S, Barker M, et al. Process evaluation of complex interventions: UK medical research council (RC) guidance, 2015.

105. Neuendorf K. The content analysis guidebook. USA: Cleveland State university, Sage publications inc, 2017. http://www. tandfonline.com/doi/abs/

106. Kuș Saillard E. Systematic versus interpretive analysis with Two CAQDAS Packages: NVivo and MAXQDA. Forum Qualitative Sozialforschung / Forum: Qualitative Social Research, 2011.

107. Schulz R, Czaja SJ, Lustig A, et al. Improving the quality of life of caregivers of persons with spinal cord injury: a randomized controlled trial. Rehabil Psychol 2009;54:1-15.

108. Ergh TC, Rapport LJ, Coleman RD, et al. Predictors of caregiver and family functioning following traumatic brain injury: social support moderates caregiver distress. J Head Trauma Rehabil 2002:17:155-74.

109. Zimmerman MA. Psychological empowerment: issues and illustrations. Am J Community Psychol 1995;23:581-99.

110. Smit B, Van Gennep ATG. Netwerken van mensen met een verstandelijke handicap. Werken aan sociale relaties: praktijk en theorie. [Social networks of people with intellectual disabilities. Working at social relations: practice and theory]. NIZW: Utrecht, 1999.

111. Witteveen E, van GS. Heel het leven [Entire life]. Hogeschool Utrecht, Kenniscentrum Sociale Innovatie: Utrecht, 2015.

112. Vilans. Toolkit, persoonsgerichte zorg [Toolkit, person-centred care]. 2015. Utrecht.

113. Verhage F. Intelligentie en leeftijd: Onderzoek bij Nederlanders van twaalf tot zevenenzeventig jaar [Intelligence and age: Research among Dutch people from twelve to seventy-seven years]. Assen: Van Gorcum, 1964.

114. Post MW, van de Port IG, Kap B, et al. Development and validation of the Utrecht Scale for Evaluation of Clinical Rehabilitation (USER). Clin Rehabil 2009;23:909-17.

115. Nasreddine ZS, Phillips NA, Bédirian V, et al. The montreal cognitive assessment, MoCA: a brief screening tool for mild cognitive impairment. J Am Geriatr Soc 2005;53:695-9.

116. Kirshblum SC, Burns SP, Biering-Sorensen F, et al. International standards for neurological classification of spinal cord injury (revised 2011). J Spinal Cord Med 2011;34:535-46.

117. Rommers GM, Ryall NH, Kap A, et al. The mobility scale for lower limb amputees: the SIGAM/WAP mobility scale. Disabil Rehabil 2008;30:1106-15.

118. Ryall NH, Eyres SB, Neumann VC, et al. The SIGAM mobility grades: a new population-specific measure for lower limb amputees. Disabil Rehabil 2003;25:833-44.

119. Bamford J, Sandercock P, Dennis M, et al. Classification and natural history of clinically identifiable subtypes of cerebral infarction. Lancet 1991;337:1521-6.
120. Deelman BG, Koning-Haanstra M, Liebrand WBG, et al. SAN Test, een afasie test voor auditief en mondeling taalgebruik [SAN Test, a aphasia test for auditory and oral language]. Lisse: Swets \& Zeitlinger, 1981.

121. Brott T, Adams HP, Olinger CP, et al. Measurements of acute cerebral infarction: a clinical examination scale. Stroke 1989:20:864-70.

122. Sanderman R, Arrindell WA, Ranchor A V, et al. Het meten van persoonlijkheidskenmerken met de Eysenck Personality Questionnaire (EPQ), een handleiding [Measuring personality characteristics with the Eysenck Personality Questionnaire (EPQ), a guide]. 2nd edn. Groningen: UMCG / Rijksuniversiteit Groningen, Research Institute SHARE, 2012.

123. Sanderman R, Eysenck SBG, Arrindell WA. Cross-cultural comparisons of personality: the Netherlands and England. Psychol Rep 1991;69:1091-6.

124. Bode C, Thoolen B, De Ridder D. Measuring proactive coping. Psychometric characteristics of the Utrecht Proactive Coping Competence scale (UPCC). Psychol Gezondh 2008;32:81-91.

125. Schreurs PJG, Tellegen B, Van de Willige G. Gezondheid, stress en coping: de ontwikkeling van de utrechtse coping lijst [health, stress and coping: the development of the Utrecht Coping List]. Tijdschr voor Psychol 1984:12:101-17.

126. Schreurs PJG, Van de Willige G, Brosschot JF, et al. Handleiding Utrechtse Coping Lijst UCL (herziene versie) [Manual Utrecht Coping List UCL (revised)]. Lisse: Swets \& Zeitlinger, 1993.

127. Ferguson E, Matthews G, Cox T. The Appraisal of Life Events (ALE) scale: reliability and validity. $\mathrm{Br} \mathrm{J}$ Health Psychol 1999;4:97-116.

128. Connor KM, Davidson JR. Development of a new resilience scale: the Connor-Davidson Resilience Scale (CD-RISC). Depress Anxiety 2003;18:76-82.

129. Schulenberg SE, Schnetzer LW, Buchanan EM. The purpose in life test-short form: development and psychometric support. $J$ Happiness Stud 2011;12:861-76.

130. Schulenberg SE, Melton AMA. A confirmatory factor-analytic evaluation of the purpose in life test: preliminary psychometric support for a replicable two-factor model. $J$ Happiness Stud 2010;11:95-111.

131. Epstein NB, Baldwin LM, Bishop DS. THE Mcmaster family assessment device*. J Marital Fam Ther 1983;9:171-80.

132. Van Eijk LM, Kempen G, Van Sonderen FLP. Een korte schaal voor het meten van sociale steun bij ouderen: De SSL12-I [A short scale for measuring social support in the elderly: The SSL12-I]. Tijdschr Gerontol Geriatr 1994;25:192-2.

133. Kempen GIJM, Van Eijk LM. The psychometric properties of the SSL12-I, a short scale for measuring social support in the elderly. Soc Indic Res 1995;35:303-12. 